\title{
Structural Characteristics and Application in Cigarette Filter of Castor Based Porous Materials
}

\author{
Ling ZHANG, Tiandong ZHANG, Wenyuan WANG, Bo CAI, Qianxu YANG \\ R\&D Center \\ China Tobacco Yunnan Industrial Co., Ltd \\ Kunming, China \\ e-mail:zhang-874005@163.com
}

Jing LI

Faculty of architectural engineering

Yunnan agricultural university

Kunming, China

e-mail:119026815@qq.com

\begin{abstract}
Porous materials with high specific surface areas was prepared by a combined method of microwave drying carbonization and activation processes, in which castor rhizome was used as carbon source, and $\mathrm{KOH}$ was used as activator, respectively. The porous material was added to the cigarette filters and the adsorption performance of the filter composited porous material was studied. The results showed that: the material had the specific surface areas and mesoporous proportion as high as $2079.25 \mathrm{~m} 2 / \mathrm{g}$ and $\mathbf{7 9 . 1 0 \%}$, respectively. The material was activated carbon material with multi-porous structure. Compared with the control cigarettes, the filter composited porous materials could reduce the tar and seven hazardous substances of cigarette mainstream smoke, which decreased by $12.71 \%, 8.79 \%, 21.59 \%, 3.90 \%, 3.85 \%$, $19.17 \%, 3.80 \%$ and $29.75 \%$, respectively.
\end{abstract}

Keywords-castor rhizome; porous materials; cigarette filte; adsorption; sensory quality

\section{INTRODUCTION}

With the problems of smoking and health becoming prominent increasingly and the awareness of health increases, low risk cigarettes become development trend in the field of tobacco. In the process of developing low toxic cigarette, blending reconstituted tobacco sheet, blending expanded tobacco and expanded stem are usually used. The methods of reducing tar and hazardous materials are to reduce the harm of silk, filter rod drilling, ventilation and dilution, adding adsorbent material in filter rod, and applying high permeable cigarette paper.

Adding adsorption material to the filter is a kind of effective method, which made a lot of researchers study the adsorption material of tobacco industry in recent years. The reported adsorption materials such as activated carbon, zeolite, sepiolite, zeolite, silica gel, has a good effect on reducing hazardous materials, which influence the cigarette style and the sensory quality [1-4].

In order to improve the affects of adsorption materials on the cigarette, the researchers transferred adsorbed materials to the environmental friendly natural perfume plants, and its crushing of granular materials, which was applied to the cigarette filters and prepared to a certain size[5-7]. The application of porous materials in cigarette filters was researched, although degree of aroma enhancing effect, but the effect of hazardous materials reducing was not obvious.

Currently, the study of single plant material is mainly concentrated in the characteristics, and for the formulation and study the specific modification of porous material. has good adsorption effect. The castor rhizome was used as carbon source, and $\mathrm{KOH}$ was used as activator, respectively, which the application in cigarettes was studied furtherly. The porous material has wide source of raw materials, low cost, simple preparation process, a selective adsorption and filtration of cigarette smoke.

\section{MATERIALS AND METHODS}

Tow (2.7/35000 specification, 3.9/31000 specification, $3.0 / 35000$ specification), cut tobacco of Yunnan China Tobacco Industry company; porous material, homemade; Mill (TQ-2000Y), Yongkang Yunda mechanical equipment factory; standard sample sieve $(40,60)$, Shanghai special equipment; fluidized bed (Mini Glatt type), Germany Glatt company; tube furnace (GSL-1600X), Shanghai Precision Instrument; desktop (QUANTA-TA200 type scanning electron microscope), America FEI; specific surface area and pore size analyzer (NOVA2200e), the United States Contador instrument company; infrared spectrometer (Bruker TENSOR27), the German company Brook; filter rod forming machine (KDF-2E type), Shenyang aircraft manufacturing company; filter rod forming machine (KDF-2 type), Shenyang aircraft manufacturing company; composite molding machine (JK3D type) Shenyang aircraft manufacturing company; channel rotary smoking machine (type HBRM/CS20), the German Borgwaldt Technik company; gas chromatography (Trace-2000), the United States Agilent; gas chromatography (HP6890), the United States. Jielun; mass spectrometry detector (HP5793), the 
Agilent in the United States. Extraction equipment, homemade.

The castor rhizome was crushed and sprayed in a fluidized bed. The prepared material was irregular granular particles. The particles was then placed in a tube furnace (GSL-1600X, Ningbo Opple Instrument, China) and heated at a rate of $5 \sim 20^{\circ} \mathrm{C} / \mathrm{min}$ until $350^{\circ} \mathrm{C}$ for $30 \mathrm{~min}$ under nitrogen atmosphere. The particle was cleaned by deionized water until the $\mathrm{pH}$ of the washing fluid reach to neutral. Then the particles was heat treated under vacuum at $90^{\circ} \mathrm{C}$ for 4h.KOH and the particles was put in tube furnace according to the quality of $4: 1$, which was heated for $15 \mathrm{~min}$ at $600^{\circ} \mathrm{C}$ under nitrogen atmosphere. And the porous materials was filtered and washed with $\mathrm{HCl}$ solution (mass fraction, $10 \%)$.And then it was cleaned by deionized water until the $\mathrm{pH}$ of the washing fluid reach to neutral. Finally, the resulting porous materials was dried at $110^{\circ} \mathrm{C}$ to a constant mass, filtered with a $850 \mu \mathrm{m}$ screen, placed in polyethylene bags and stored in a dryer.

Cigarette filters were prepared as follows: $60 \pm 1 \mathrm{mg}$ of the carbon granules were weighed into the cavity of a cigarette filter of a $24.6 \mathrm{~mm}$ circumference cigarette, made up of a $56 \mathrm{~mm}$ long cigarette rod containing a Virginia-style tobacco blend (tobacco rod density of $255 \mathrm{mg} \mathrm{cm}-3$ at a moisture content of $13 \%$ ) and a $27 \mathrm{~mm}$ length three part cavity filter $(10 \mathrm{~mm}$ cellulose acetate at the rod end, $4 \mathrm{~mm}$ cavity and $13 \mathrm{~mm}$ cellulose acetate at the mouth end). Triacetin is used as a plasticizer on cellulose acetate filter sections and loadings of $10 \%$ and $6 \%$ by weight for the end and rod end segments, respectively. Cigarette filters were all unventilated (i.e. noair vent holes are made to allow influx of air during puffing). A standard $50 \mathrm{CU}$ permeability cigarette paper was used throughout [where $1 \mathrm{CU}$ is the flow of air (cm3/minute) passing through $1 \mathrm{~cm} 2$ surface of the test piece at a measuring pressure of $1.00 \mathrm{KPa}$ ]. As a control, cigarettes of the same dimensions and composition were also prepared with an empty $4 \mathrm{~mm}$ filter cavity section. To mimic manufacturing conditions, the cigarettes were conditioned at $22{ }^{\circ} \mathrm{C}$ and $60 \%$ relative humidity for 3 weeks following the inclusion of carbon in the cigarette filter and then smoke dunder ISO smoking conditions (one $35 \mathrm{ml}$ volume puff of 2second duration taken every minute)(International Organisation for Standardization 1991; Thomsen 1992).

The surface morphologie of the samples were examined by field emission scanning electron microscopy (QUANTATA200, FEI, USA).The pore properties of the samples were estimated by nitrogen adsorption-desorption isotherms at 77 $\mathrm{K}$ using the specific surface areas and pore-size analyzer (NOVA2200e, Quanta chrome, USA).The Multipoint Brunauer-Emmett-Teller (BET) equation was used to calculate specific surface area of the samples. The total pore volume was acquired from the adsorptive amount of nitrogen at $\mathrm{P} / \mathrm{P} 0=0.98$. Organic functional groups were characterized by Fourier transformation infrared analysis (Bruker TENSOR27, BRUKER, Germany).According to GB5606.42005[8], sensory evaluation was evaluated by professional assessment staffs. Standard Test Method for determination of nicotine, tar and $\mathrm{CO}$ content in cigarette smoke: determination of total particulate matter and tar in
GB/T19609-2004 cigarette by routine analysis with cigarette smoking machine [9].Standard method for the determination of mainstream cigarette smoke: cigarette mainstream smoke in GB5606.5-2005 [10]. Mainstream cigarette smoke of low molecular aldehydes and ketones, hydrocyanic acid, polycyclic aromatic hydrocarbons and ammonia ion detection according to YC/T 253-2008, YC/T 254-2008 and GB/T 130-2007[11-13].

\section{RESULTS AND DISCUSSIONS}

\section{A. Microscopic Morphology}

The SEM images analysis results of unmodified carbonized porous materials (a) and he modified porous materials (b). The results show that the surface is rough, and the shape of the strip shape is irregular. From figure 3(b) it can be seen that the surface exhibits a large number of holes and pores after modifying treatment. The pore distribution is disordered and irregular, and the holes connected to each other to form a network. The reason for the results is that chemical reactions occur between the materials and $\mathrm{KOH}$ during the thermal treatment. From Fig.1, the surface morphology of the material changes significantly and obtains a lot of cavities and pores by modifying treatment, which obviously increases the specific surface area. Greater specific surface areas are generally correlated with better adsorption performance. Therefore, the structure of the samples is better for adsorption. When the aerosol flows through the flue gas, the retention probability of the aerosol particles is increased by the morphology structure, which can prolong and interfere the movement time and trajectory of aerosol particles, so as to obtain higher adsorption and interception efficiency.

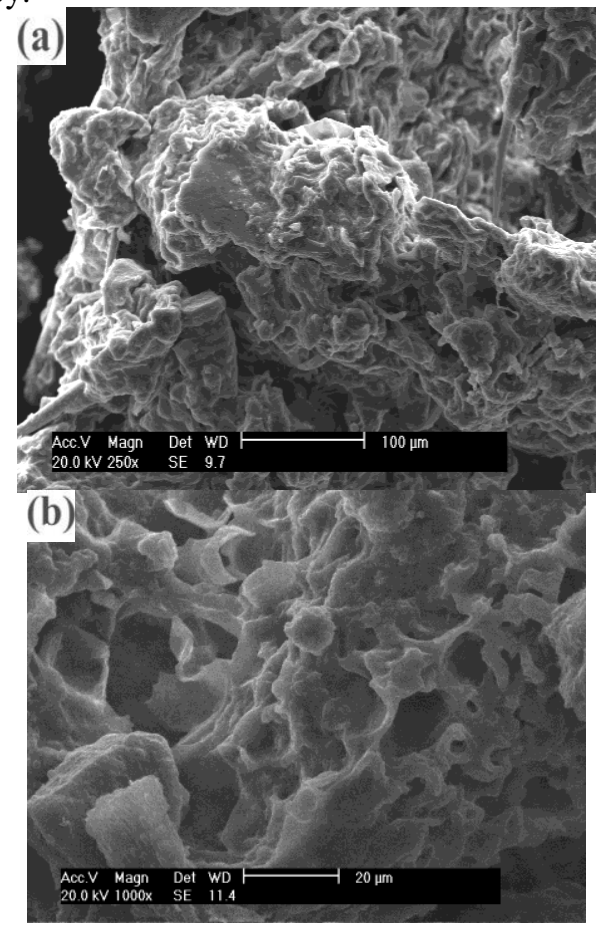

Figure 1. SEM images of unmodified carbonized porous materials (a) and the modified porous materials (b). 


\section{B. Pore Structure}

The Brunauer-Emmett-Teller test was carried out on the samples and the results are shown inTable3. The results show that the specific surface and the pores volumes (Vtotal) of the materials significantly increased to $2079.25 \mathrm{~m}^{2} / \mathrm{g}$ and 0.68 $\mathrm{cm} 3 / \mathrm{g}$, respectively. The mesoporous proportion is as high as $79.10 \%$. This dramatic increase in surface areas and pore volumes are as a result of the chemical reactions occurring between $\mathrm{NaOH}$ and the materials. The reactions are given below:

$$
\begin{gathered}
6 \mathrm{KOH}+2 \mathrm{C} \longrightarrow 2 \mathrm{~K}+3 \mathrm{H}_{2}+2 \mathrm{~K}_{2} \mathrm{CO}_{3} \\
2 \mathrm{C}+\mathrm{K}_{2} \mathrm{CO}_{3} \longleftrightarrow 2 \mathrm{~K}+3 \mathrm{CO}
\end{gathered}
$$

The pore-size distribution was investigated and the results are shown in Fig.2. It can be seen that the pore size is mainly concentrated in the range of $5.7 \sim 11 \mathrm{~nm}$, which indicates that the pore structure is mainly based on the larger mesoporous structure and has certain smaller microporous structure [14-16]. In addition, some studies have shown that the pore size of aporous material determines the specific surface areas and pore volumes of the material, which affects its adsorption capacity [17]. The smaller pore size is better for adsorption, but very small pore sizes can be blocked by the adsorbate. Therefore, the pore size of the porous materials is suitable for adsorbate channels, with capillary condensation under certain pressures, which is better for the adsorption of large molecules.

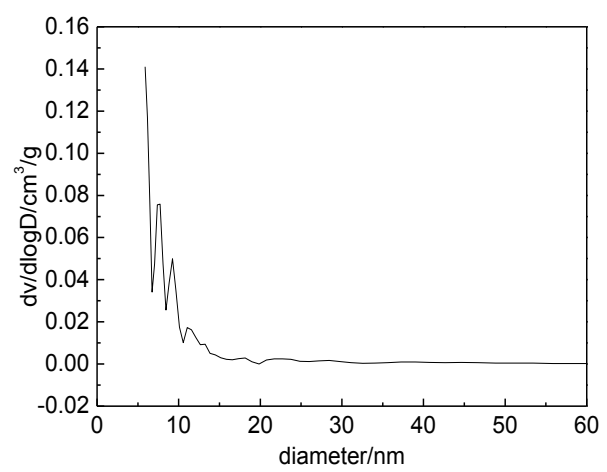

Figure 2. Pore size distribution of porous materials.

\section{Surface Functional Groups}

The FTIR spectrograms of unmodified and modified porous materials were shown in Fig.5. Special functional groups corresponding to the absorption position were analyzed according to the literatures $[18,19]$. In the FTIR analysis, the strong peak near $3418.13 \mathrm{~cm}-1$ is attributed to the hybrid stretching vibration of $\mathrm{O}-\mathrm{H}$ and $\mathrm{N}-\mathrm{H}$, and the peak near $2923.08 \mathrm{~cm}-1$ is probably the peak of $\mathrm{CH} 2$ and $\mathrm{CH} 3$. The strong peak near $1637.03 \mathrm{~cm}^{-1}$ is the $\mathrm{N}-\mathrm{H}$ stretching vibration of the primary amine, the strong peak near $1032.58 \mathrm{~cm}^{-1}$ is the absorption band of the C-O-C symmetric and asymmetric stretching vibrations and the $\mathrm{O}-\mathrm{H}$ unbalanced surface rocking vibration of the carboxyl group molecular aggregates, and the peak near $606.05 \mathrm{~cm}^{-1}$ is the absorption band of SO42-. According to the above analysis, the material has many functional groups, such as hydroxyl, amine, and carboxyl groups and non-carbon elements. These kinds of functional groups could result in improving polar, hydrophilic, catalytic performance and changing the surface charge, which can enhance the interaction between the adsorbent and adsorbate. Thus, the porous material will have a better adsorption capacity [20].

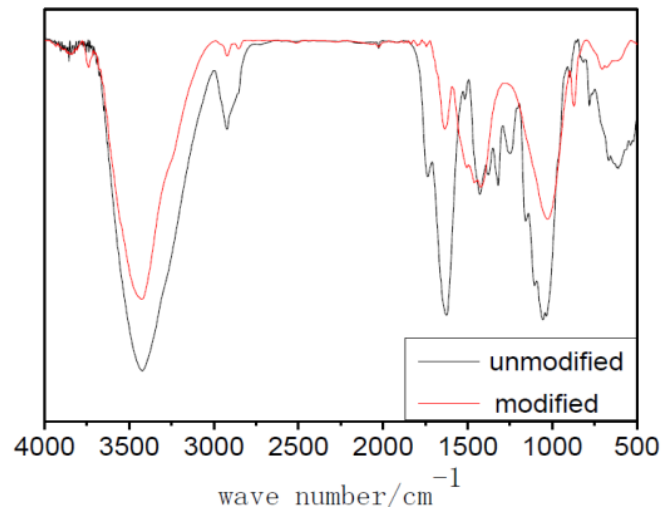

Figure 3. IR spectra of unmodified and modified porous materials.

The FTIR spectrograms of unmodified and modified porous materials were compared. The spectrograms were roughly similar regardless of treatment condition, but the intensity of each stretching vibration peak significantly changed after modification, which indicates that modification can increase the functional groups of $-\mathrm{OH}$ and $-\mathrm{CH}$. It shows that the material has a certain pro organic.

\section{Flue Gas Analysis of Composite Filter with Porous Material}

Table 1 shows the results of conventional flue gas analysis. The total particulate matter decreased by $1.64 \mathrm{mg} /$ (11.68\%), tar decreased by $1.49 \mathrm{mg} /(12.79 \%)$, CO decreased by $1.12 \mathrm{mg} /(8.78 \%)$, and nicotine did not change obvious comparing with the control samples. Adding porous materials to the filter can reduce the total particulate matter, tar and $\mathrm{CO}$ of main stream cigarette smoke. According to the analysis, the abundant pores and net structures of the porous materials could result in increasing a large number of specific surface areas and pore volumes, which increased the probability of retention of aerosols. At the same time ,the porous materials possess many functional groups, such as hydroxyl, amine, and carboxyl groups, which can enhance the interaction between the adsorbent and adsorbate. While, the existence form of nicotine is the same as the particle phase, but the good volatile make it easy to be washed by fresh flue gas. Thus, the filter effect on nicotine is not very obvious.

\section{E. Effect of Porous Material Composite Filter on Seven Harmful Substances}

Table 2 was the test results of tobacco harmful composition. It indicates that the seven harmful ingredients in the cigarette with porous materials decreased in different degrees compared with the control sample, in which $\mathrm{CO}$ decreased by $8.78 \%$, B (a) P decreased by $21.61 \%$, NNK decreased by $3.91 \%$, crotonaldehyde decreased by $3.82 \%$, HCN decreased by $3.90 \%$, phenol decreased $29.79 \%$. 
TABLE I. GENERAL INDEXES OF CIGARETTE

\begin{tabular}{|c|c|c|c|c|c|}
\hline sample & $\begin{array}{l}\text { total } \\
\text { particulate } \\
\text { matter } / \mathrm{mg} / \\
\text { branch }\end{array}$ & $\begin{array}{c}\operatorname{tar} \\
/ \mathrm{mg} / \text { branch }\end{array}$ & $\begin{array}{l}\text { smoking } \\
\text { nicotine/mg/ } \\
\text { branch }\end{array}$ & $\begin{array}{c}\mathrm{CO} \\
/ \mathrm{mg} / \text { branch }\end{array}$ & $\begin{array}{l}\text { moisture content } \\
/ \mathrm{mg} / \text { branch }\end{array}$ \\
\hline $\begin{array}{l}\text { contral } \\
\text { cigarette }\end{array}$ & 14.04 & 11.65 & 1.09 & 12.75 & 1.3 \\
\hline $\begin{array}{c}\text { Test } \\
\text { cigarette }\end{array}$ & 12.4 & 10.16 & 1.06 & 11.63 & 1.2 \\
\hline $\begin{array}{l}\text { Change } \\
\text { rate\% }\end{array}$ & 11.68 & 12.79 & 2.75 & 8.78 & 7.69 \\
\hline
\end{tabular}

Note: The values of the content are the average values from three duplicate tests.

TABLE II. DETECTION RESULTS OF HARMFUL COMPONENTS

\begin{tabular}{|c|c|c|c|c|c|c|c|}
\hline Sample & $\begin{array}{c}\mathrm{CO} \\
/ \mathrm{mg} / \\
\text { branch }\end{array}$ & $\begin{array}{c}\text { B(a)P } \\
\text { /ng/ } \\
\text { branch }\end{array}$ & $\begin{array}{c}\text { NNK } \\
\text { /ng/ } \\
\text { branch }\end{array}$ & $\begin{array}{c}\text { crotonald } \\
\text { ehyde } \\
/ \mu \mathrm{g} / \\
\text { branch } \\
\end{array}$ & $\begin{array}{c}\mathrm{HCN} \\
/ \mu \mathrm{g} / \\
\text { branch }\end{array}$ & $\begin{array}{c}\mathrm{NH}_{3} \\
/ \mu \mathrm{g} / \\
\text { branch }\end{array}$ & $\begin{array}{c}\text { Phenol } \\
/ \mu \mathrm{g} / \\
\text { branch }\end{array}$ \\
\hline $\begin{array}{c}\text { contral } \\
\text { cigarette }\end{array}$ & 12.75 & 9.3 & 2.56 & 17.8 & 115.7 & 5.9 & 19.2 \\
\hline test cigarette & 11.63 & 7.29 & 2.46 & 17.12 & 94.33 & 5.67 & 13.48 \\
\hline change rate $\%$ & 8.78 & 21.61 & 3.91 & 3.82 & 18.47 & 3.90 & 29.79 \\
\hline
\end{tabular}

Note: The values of the content are the average values from three duplicate tests.

Comparing with the ordinary fiber filter, the reduction effect of phenol, HCN (hydrocyanic acid) and B (a) P (benzo (a) pyrene) in the composite filter rod adding porous materials is obvious, which is because the porous material modified by $\mathrm{NaOH}$ treatment, although the distilled water washing on the surface, but the residual and porous materials still showed weak alkaline, so the reduction effect of acidic harmful substances is obvious.

\section{F. Sensory Evaluation of Cigarette}

Compared with control cigarettes, the sensory score of the cigarettes adding the porous materials increased 1.3 points, which results in that the sensory quality of cigarettes has been significantly improved, while maintaining the overall style of the same cigarette aroma, more abundant, smoke concentration increases, the irritation reduces, and the aftertaste improves.

\section{CONCLUSIONS}

(1) The porous material was activated carbon with multiporous structure, whcih possesses the specific surface areas and mesoporous proportion as high as $2079.25 \mathrm{~m} 2 / \mathrm{g}$ and $79.10 \%$, respectively.

(2) The porous materials possess many functional groups, such as hydroxyl, amine, and carboxyl groups, which can enhance the adsorption capacity.

(3) Compared with the control cigarettes, the filter composited porous materials could reduce the tar and seven hazardous substances of cigarette mainstream smoke, which decreased by $12.71 \%, 8.79 \%, 21.59 \%, 3.90 \%, 3.85 \%$, $19.17 \%, 3.80 \%$ and $29.75 \%$, respectively.

(3) Compared with the conventional filter, the filter composited porous materials could enrich the smoke, enhance the smoke concentration, reduce the irritation and improve the aftertaste.

\section{ACKNOWLEDGMENT}

This work was supported financially by China Tobacco Yunnan Industrial Co., Ltd. (project number: 2017CP04).

\section{REFERENCES}

[1] M Ashley, A Sisodiya, M Mcewan, "Comparison of mouth level exposure to 'Tar' and nicotine in smokers of normal and superslim king size cigarettes in Romania," Beiträge Zur Tabakforschung, vol.24, Dec.2014, pp.277-288.

[2] C Nie, L Zhao, B Peng, XH Sun, QG Yang ,'Studies on postsynthesized amine-functionalized materials for reducing volatile carbonyl compounds in cigarette smoke ,"Acta Tabacaria Sinica, vol.16, Dec.2010, pp.5054,Doi:10.3969/j.issn.100457082010.z1.011.

[3] M Y Xu, P Yin, XG Liu, QH Tang, RJ Qu, Q Xu, "Utilization of rice husk modified by organo multi phosphonic acids as low-cost absorbents forenhanced adsorption of heavy metal ions," Bioresource Technology, vol.149, Dec.2013,pp.420-424,doi: org /10.1016/ j.biortech.2013.09.075.

[4] WP Gong, ZY Sheng ,YX Chen, SL Zhou, XM Qi, "Study on removal of $\mathrm{B}[\mathrm{a}] \mathrm{P}$ and phenol from mainstream smoke of cigarette by using zeolites, "Science and Technology of Food Industry,vol.34, Nov.2013, pp.104-106.

[5] QL Liu, JH Liu, JJ Liu, "Research and progress of exploitation and utilization of Chinese herbal medicine resources ," Bulletin of Biology, vol.36,2001, pp.45-46. 
[6] XZ Zheng, SH Zhang, JQ Qiu, "Research progress of tar reducing and harm reducing technology," tobacco science and technology, vol.196, Nov.2003, pp.8-13.

[7] ZY Yao, T Ma, DQ Wen, XZ Huang, LL Luo, "Application of microwave expansion application of chemical tobacco stalk granule in cigarette filter rod,"vol.39,Sep.2010,pp.1432-1435.

[8] GB 5606.4-2005The State Tobacco Monopoly Bureau. Hydrogen cyanide in mainstream cigarette smoke determination [S]. Beijing: Standards Press China.2008.

[9] GB/T19609-2004 Determination of total particulate matter and tar in cigarette by routine analysis[S].

[10] GB 5606.5-2005 National Tobacco Monopoly Bureau. Cigarette mainstream smoke [S] .

[11] YC / T 253-2008State Tobacco Monopoly Bureau. Determination of hydrogen cyanide in main stream cigarette smoke[S] . Beijing: Standards Press Chinese.2008.

[12] YC / T 254-2008 National Tobacco Monopoly Bureau Determination of major carbonyl compounds in mainstream cigarette smoke of. of [S]. Beijing: China standard press, 2008.

[13] GB / T 21130-2007 Zhengzhou Tobacco Research Institute, China National Tobacco Corp Determination of benzo [a] pyrene in total particulate matter of cigarette smoke [S]. Beijing: China National Standard Press, 2007.

[14] J H Zhang, S M Xie, M Zhang, M Zi, PG He, LM Yuan, "Novel inorganic mesoporous material with chiralnematic structure derived from nanocrystalline cellulose for high-resolution gas chromatographic separations," Anal Chem, vol.86,2014,pp.95959602, doi: 10.1021/ ac502 073g.

[15] S H, Joo;S J, Choi;I, Oh;J, Kwak;Z, Liu;O, Terasaki;R, Ryoo, "Ordered nanoporous arrays of carbon supporting high dispersions of platinum nanoparticles," Nature, vol.414, 2001, pp.470-470.

[16] L Y Yuan, YL Liu, W Q Shi, ZJ Li, JH Lan, YX Feng, YL Zhao, YL Yuan, ZF Cai, "A novel mesoporous material for uranium extraction, dihydroimidazole functionalized SBA-15," J Mater Chem,vol.22, Jun.2012,pp.17019-17026,doi: 10.1039/C2JM31766D

[17] SP Sturgis," A spectral-analysis tutorial with examples in FORTRAN" Behavior Research Methods \&Instrumentation, vol.15, 1983, pp.377-386.

[18] R Gong, YZ Sun, J Chen, HJ Liu ,C Yang, "Effect of chemical modification on dye adsorption capacity of peanut hull," Dyes and Pigments, vol.67,2005,pp.175-181,doi: org/10.1016/j. dyepig. 2004.12. 003.

[19] RP Han, WH Zhou, JH Zhang, J Shi, JJ Yang, "Characterization of chaff and biosorption of copper and lead ions from aqueous solution" Acta Scientiae Circumstantiae,vol.26,Jan. 2006,pp. 32 - 39.

[20] Y Xia, R Mokaya, GS Walker, Y Zhu, "Superior CO2 adsorption capacity on Ndoped, high-surface-area, microporous carbons templated from zeolite," Advanced Energy Materials, vol.1,2011,pp. 678-683,doi: 10.1002/aenm.201100061. 